УДК $681.518+332.6$

DOI 10.18413/2712-7443-2020-44-1-55-63

\title{
Применение геоинформационных систем при проведении кадастровой оценки объектов недвижимости в Российской Федерации
}

\author{
А.В. Осенняя, И.С. Грибкова, Б.А. Хахук, Т.А. Бацких, К.В. Воронова \\ Кубанский государственный технологический университет, \\ Россия, 350072, г. Краснодар, ул. Московская, 2 \\ E-mail: avosen2910@yandex.ru, i.s.gribkova@mail.ru
}

\begin{abstract}
Аннотация. Преимущества использования геоинформационных технологий в кадастровой оценке, от результата осуществления которой зависят отношения между налогоплательщиком собственником объекта недвижимости и налогополучателем - муниципальным образованием, неоспоримы. Однако роль и значение автоматизации процессов осуществления анализа и вопросов реализации этапов кадастровой оценки во всей системе кадастрово-оценочных работ и налогообложения объектов недвижимости не в полной мере раскрыты в научной литературе. В связи с этим авторами проведены исследования возможностей применения ГИС при определении значений ценообразующих факторов, осуществления оценочного зонирования территории и другие; осуществлен анализ отчётов и проектов отчётов об итогах государственной кадастровой оценки земельных участков и объектов капитального строительства в составе земель населенных пунктов; выявлены основные направления применения ГИС в субъектах страны в рамках определения кадастровой стоимости объектов оценки; определены регионы, использующие для оценки недвижимости цифровые тематические карты, а также регионы, применяющие функциональные возможности геоинформационных систем.
\end{abstract}

Ключевые слова: кадастровая оценка, недвижимость, объект оценки, ГИС, MapInfo, QGIS.

Благодарности: исследование выполнено при финансовой поддержке РФФИ и Администрации Краснодарского края в рамках научного проекта № 19-410-230062.

Для цитирования: Осенняя А.В., Грибкова И.С., Хахук Б.А., Бацких Т.А., Воронова К.В. 2020. Применение ГИС при проведении кадастровой оценки объектов недвижимости в Российской Федерации. Региональные геосистемы, 44(1): 55-63. DOI 10.18413/2712-7443-2020-44-1-55-63

\section{Application of geoinformation systems when carrying out the cadastral assessment of real estate objects in the Russian Federation}

\author{
Anna V. Osennyaya, Irina S. Gribkova, Bela A. Khakhuk, \\ Tatyana A. Batskikh, KseniyaV. Voronova \\ Kuban State Technological University, \\ 2 Moskovskaya St, Krasnodar, 350072, Russia \\ E-mail: avosen2910@yandex.ru, i.s.gribkova@mail.ru
}

\begin{abstract}
Geographic information technology has now established itself in various fields of application. The advantages of their use, especially in the cadastral valuation, on the outcome of which the relationship between the taxpayer - the owner of the property and the tax receiver - the municipality depends, are undeniable. However, the role and importance of automating the processes of analysis and
\end{abstract}


questions of the implementation of the stages of cadastral valuation in the entire system of cadastral valuation and taxation of real estate are not fully disclosed in the scientific literature. For many types of spatial operations used at different stages of the cadastral valuation, the end result is the presentation of data in the form of thematic maps and plans, supplemented, if necessary, by reporting documents, threedimensional images, graphs, charts and tables, photographs and other means. In this regard, the possibilities of using GIS during cadastral valuation were considered, among which were calculations of the values of pricing factors, estimated zoning of the territory, and others. The analysis of reports and draft reports on the results of the state cadastral valuation of land plots and capital construction objects in the land of settlements was carried out. The main directions of the use of GIS in the regions in the framework of determining the cadastral value of valuation objects are identified. At the initial stage of the cadastral assessment should be used GIS. GIS is a multifunctional information system designed to collect, store, analyze and graphically visualize spatial data and related information about the necessary objects, which allows you to combine, organize and display on the map relevant and reliable data from various information systems. The most used are MapInfo and QGIS. The most important GIS functionalities in the field of assessment are identification of objects of assessment, determination and calculation of pricing factors, estimated zoning of the territory, georeferencing of objects of cadastral assessment, transformation of coordinate systems. The article substantiates the possibility of using GIS in carrying out cadastral valuation, including the calculation of the values of pricing factors, estimated zoning of the territory, and others. The regions using digital thematic maps for real estate assessment, as well as regions using the functionality of geographic information systems were identified.

Key words: cadastral valuation, real estate, valuation object, GIS, MapInfo, QGIS.

Acknowledgements: The reported study was funded by RFBR and the Administration of the Krasnodar Territory, project number 19-410-230062.

For citation: Osennyaya A.V., Gribkova I.S., Khakhuk B.A., Batskikh T.A., Voronova K.V. 2020. GIS application when carrying out the cadastral assessment of real estate objects in the Russian Federation. Regional Geosystems, 44(1): 41-54. DOI: 10.18413/2712-7443-2020-44-1-55-63

\section{Введение}

Современная концепция идеологов кадастровой оценки заключается в достижении максимального сближения показателей кадастровой и рыночной стоимостей ввиду того, что рыночная стоимость, рассчитываемая методами индивидуальной оценки, является более объективным показателем, чем кадастровая стоимость, базирующаяся на методах массовой оценки. Однако при расчете данных видов стоимостей обязательным условием является наличие обновляющейся информационной системы, содержащей актуальные показатели, ценообразующие факторы с определением их количественных характеристик, влияющих на стоимость объектов на рынке недвижимости, что может быть реализовано исключительно на основе геоинформационных технологий в связи с необходимостью обязательного проведения анализа по картографическим и тематическим базам данных.

Анализ и перспективы применения потенциальных возможностей ГИС в кадастровой оценке, неоспоримы. [Головина, 2018; Козырев, Шумаева, 2019]. На сегодняшний день результаты кадастровой оценки определяют размеры налоговых и арендных платежей [Грибовский, 2017; Суровцов и др., 2017]. При этом процедура определения стоимости имеет массу недостатков уже на этапе сбора сведений об объектах недвижимости, так как информация, содержащаяся в базе данных Единого государственного реестра недвижимости, зачастую не только неактуальна, но и противоречит действительности [Гридина, Гридин, 2016; Лаврова, Ефанова, 2016; Малюк, 2017]. В связи с этим Тем не менее, исследователи, применяя различные аналитические методы, не всегда задумываются о роли автоматизации процессов проведения анализа и реализации этапов кадастровой оценки и актуализации сведений во всей системе кадастрово-оценочных работ и налогообложения объектов не- 
движимости. В связи с этим авторами поставлена цель - исследовать возможности применения гис-технологий в кадастровой оценке для проведения более тщательного анализа рынка недвижимости, наполнения информационной базы ЕГРН, адекватного определения стоимости объектов недвижимости, а также возможностей осуществления их постоянного мониторинга.

\section{Объекты и методы}

В целях исследования потенциальных возможностей ГИС в кадастровой оценке был проведён анализ отчётов и проектов отчётов об итогах государственной кадастровой оценки земельных участков и объектов капитального строительства в составе земель населенных пунктов в 24 регионах страны, информация о которых представлена на официальном сайте Росреестра.

Оценка применения ГИС в субъектах показала, что наиболее используемыми ГИС в процедуре реализации оценки недвижимости являются MapInfo и QGIS. Специализированное программное обеспечение (СПО) MapInfo легко интегрируется в любую информационную систему и поддерживает все распространенные форматы данных. Также возможно использование изображений практически любых форматов (аэроснимков, спутниковых многозональных снимков, сканированных бумажных карт и др.). Помимо этого, MapInfo имеет доступ к гибридным картам. Функциональные возможности программы позволяют изменять как графические, так и семантические данные. Имеется возможность отображения на карте символами или цветом рассчитанных величин и значений при условии использования статистических и математических функций. В качестве примера в оценке недвижимости разной ценовой категории на определенной территории объекты могут быть воспроизведены соответствующими цветами [MapInfo, 2019].

$Q G I S$ - это ГИС с открытым кодом, даёт возможность пользователям, работающим на различных операционных системах, визуализировать, управлять, анализировать и редактировать данные, а также подготавливать печатные карты. ГИС поддерживает всевозможные векторные и растровые форматы, базы данных. Имеет широкий набор встроенных инструментов, таких как опознавание и выборка объектов, редактирование, просмотр, поиск атрибутивной информации, изменение символики слоёв, компоновка карт и др. В области оценки данная программа, наравне с MapInfo, позволяет группировать объекты недвижимости, выделять их по ценовым категориям и иным признакам [QGIS, 2019].

\section{Результаты и их обсуждение}

На основании полученных результатов было выявлено, что одна группа анализируемых регионов проводит кадастровую оценку объектов недвижимости посредством формирования цифровых тематических карт (ЦТК) без использования функциональных возможностей ГИС. Другая группа при определении кадастровой стоимости объектов оценки полноценно использует возможности ГИС.

На рис. 1 представлен анализ использования в процессе кадастровой оценки недвижимого имущества ГИС и ЦТК по регионам (по данным, представленным на официальном сайте Росреестра). Анализ был проведён на основании отчётов об итогах государственной кадастровой оценки.

Анализ данных, представленных на рис. 1, позволяет сделать выводы о том, что в целях проведения кадастровой оценки объектов недвижимости СПО MapInfo применяли Краснодарский край, Московская область, Москва, Санкт-Петербург и ряд других регионов. ГИС с открытым кодом QGIS была использована в Вологодской области [QGIS, 2019]. С помощью ЦТК кадастровую оценку проводили Тамбовская область, Калужская область, Саратовская область, Республика Карелия, Саха (Якутия). Наибольшее количе- 
ство анализируемых субъектов в стране (75 \%) применяет СПО MapInfo, ЦТК без использования функциональных возможностей ГИС - $21 \%$. Практически не используется (4 \%) при определении кадастровой стоимости $Q G I S$.

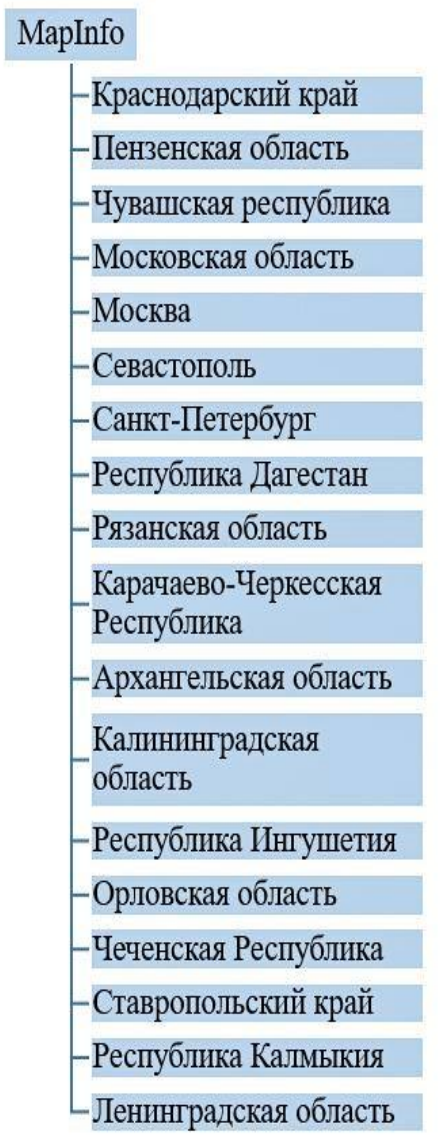

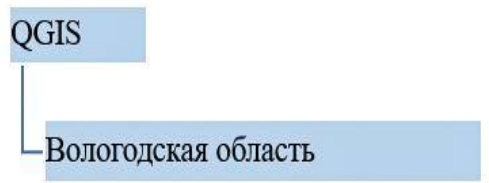

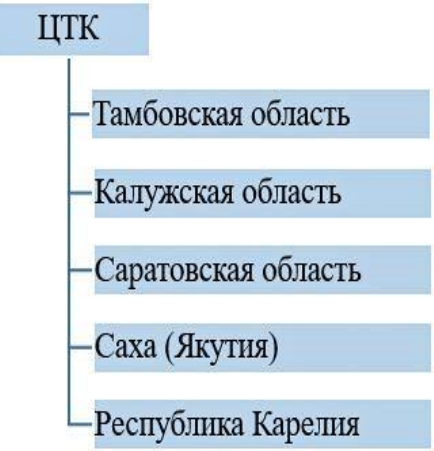

Рис. 1. Регионы, использующие в процессе кадастровой оценки ГИС, ЦТК

Fig. 1. Regions using of GIS, DTM in the process of cadastral assessment

Также следует сказать о применении регионами в процессе проведения государственной кадастровой оценки, помимо вышеуказанных ГИС, СПО «Автоматизированная оценка недвижимости» и программного комплекса (ПК) «Массовая оценка», которые работают со слоями СПО MapInfo. Основная роль СПО «Автоматизированная оценка недвижимости» и ПК «Массовая оценка» - автоматизация выполнения задач государственной кадастровой оценки объектов недвижимости и использование её результатов для целей, установленных законодательством Российской Федерации [Салин, 2017].

К функциональным возможностям СПО «Автоматизированная оценка недвижимости» относятся:

- импорт перечня объектов оценки в формате $X M L$-файлов, отображение объектов оценки, расчет количества объектов оценки;

- учёт и кодировка всех потенциально влияющих ценообразующих факторов;

- разбивка и распределение объектов оценки на оценочные группы, основываясь на сочетании значений основных параметров группировки и уточнения перечня объектов оценки;

- экспорт или импорт картографических слоев, которые необходимы для расчета графических факторов стоимости в формате MID/MIF или MapInfo; 
- автоматическая привязка объектов оценки и объектов аналогов к графическим данным, формирование слоев объектов оценки и объектов аналогов в формате $M I D / M I F$ или MapInfo;

- расчёт значений ценообразующих факторов объектов оценки и объектованалогов в формате MS Excel и MID/MIF или MapInfo;

- экспорт отчета с результатами группировки, определения ценообразующих факторов, построения моделей оценки, расчёта кадастровой стоимости объектов оценки в форматы файлов MS Excel, MID/MIF или MapInfo, MS Word [Росреестр, 2019].

Функциональные возможности ПК «Массовая оценка»:

- импорт или экспорт данных в различные форматы;

- анализ перечня объектов недвижимости;

- статистическая обработка данных;

- управление пространственными данными формата ГИС MapInfo;

- корреляционный и регрессионный анализ данных;

- формирование математических моделей оценки;

- определение кадастровой стоимости объектов недвижимости;

- анализ результатов расчёта кадастровой стоимости [Массовая оценка, 2019].

Также некоторые регионы использовали автоматизированную информационную систему (АИС) «Мониторинг рынка недвижимости», размещенную на официальном сайте Росреестра в электронном виде. Применение данной АИС позволяет получить доступ к ценам сделок в процессе систематического или непрерывного сбора информации, в следствие чего достигается принцип достаточности и репрезентативности рыночной информации.

АИС «Мониторинг рынка недвижимости» в рамках кадастровой оценки обеспечивает получение следующих сервисов:

- предоставление сведений в электронном виде об объектах и правах из Единого государственного реестра недвижимости широкому кругу лиц по запросу;

- фильтрация сведений по заданным критериям отбора, в том числе сохранение создаваемых фильтров и загрузка уже имеющихся фильтров;

- просмотр сведений об объектах на Публичной кадастровой карте;

- визуализация сведений о сделках и объектах при помощи различных типов диаграмм;

- предоставление пользователю различных видов электронных отчетов по интересующим его параметрам;

- предоставление пользователю возможности построения сводных таблиц;

- выгрузка отчетов, графиков, а также сведений о сделках и объектах на компьютер пользователя в различных форматах [Грибкова, Пастухов, 2017; Пастухов, 2018].

Использование ГИС регионами в процессе производства процедуры кадастровой оценки позволило автоматизировать некоторые аспекты определения стоимости объектов недвижимости. Направления применения ГИС в регионах при определении кадастровой стоимости обобщены в табл. 1.

Сведения, представленные в табл. 1, являются сводными и наглядно отражают направления применения ГИС при определении кадастровой стоимости объектов недвижимости в субъектах страны, а именно расчёт значений ценообразующих факторов и оценочное зонирование территории. Реже ГИС используются для преобразования систем координат, вычисления среднего, минимального и максимального значений рыночных данных, формирования базы геоданных, геопривязки объектов кадастровой оценки, а также выявления граничащих или смежных земельных участков и смежных кадастровых кварталов в пределах территориальной единицы объекта оценки. 
Направления применения ГИС в регионах в рамках этапов проведения кадастровой оценки

Directions of GIS application in the regions as part of the stages of the cadastral assessment

\begin{tabular}{|c|c|}
\hline Направление применения ГИС & Регион, год \\
\hline \multirow{5}{*}{ Расчет значений ценообразующих факторов } & Севастополь, 2018 \\
\hline & Севастополь, 2019 \\
\hline & Республика Ингушетия, 2018 \\
\hline & Республика Дагестан, 2019 \\
\hline & Чеченская Республика, 2019 \\
\hline $\begin{array}{l}\text { Идентификация объекта оценки и определения } \\
\text { ценообразующих факторов }\end{array}$ & Орловская область, 2019 \\
\hline $\begin{array}{l}\text { Выявление граничащих или смежных земельных } \\
\text { участков в пределах территориальной единицы } \\
\text { объекта оценки, установление и описание границ } \\
\text { ценовых зон }\end{array}$ & Рязанская область, 2018 \\
\hline \multirow{2}{*}{$\begin{array}{l}\text { Расчет значений ценообразующих факторов, } \\
\text { формирование базы геоданных, геопривязка объ- } \\
\text { ектов кадастровой оценки, оценочное зонирова- } \\
\text { ние территории }\end{array}$} & Москва, 2018 \\
\hline & Ставропольский край, 2019 \\
\hline $\begin{array}{l}\text { Определение ценообразующих факторов, оце- } \\
\text { ночное зонирование территории }\end{array}$ & Московская область, 2018 \\
\hline $\begin{array}{l}\text { Расчет значения ценообразующего фактора с } \\
\text { признаком «расстояние» }\end{array}$ & Пензенская область, 2018 \\
\hline $\begin{array}{l}\text { Создание карты для СПО «Автоматизированная } \\
\text { система оценки недвижимости» }\end{array}$ & Чувашская республика, 2019 \\
\hline $\begin{array}{l}\text { Оценочное зонирование территории городов, } \\
\text { установлены удельные показатели средних ры- } \\
\text { ночных цен в расчете на единицу площади }\end{array}$ & Краснодарский край, 2018 \\
\hline $\begin{array}{l}\text { Вычисление среднего, минимального и макси- } \\
\text { мального значения рыночных данных, оценочное } \\
\text { зонирование территории }\end{array}$ & Санкт Петербург, 2018 \\
\hline Оценочное зонирование территории & Карачаево-Черкесская республика, 2019 \\
\hline $\begin{array}{l}\text { Расчет значения ценообразующего фактора с } \\
\text { признаком «расстояние», определение наличия } \\
\text { преграды от земельного участка до центра насе- } \\
\text { ленного пункта (мост, ж/д пути) }\end{array}$ & Архангельская область, 2019 \\
\hline $\begin{array}{l}\text { Обработка информации, преобразование систем } \\
\text { координат }\end{array}$ & Астраханская область, 2019 \\
\hline Установление и описание границ ценовых зон & Вологодская область, 2019 \\
\hline $\begin{array}{l}\text { Формирование полигонов векторных областей } \\
\text { вокруг тех объектов недвижимости, где имеются } \\
\text { сведения, определение кадастровой стоимости } \\
\text { земельных участков }\end{array}$ & Калининградская область, 2019 \\
\hline $\begin{array}{l}\text { Оценочное зонирование территории, выявление } \\
\text { граничащих или смежных кадастровых кварталов } \\
\text { в пределах территориальной единицы объекта } \\
\text { оценки }\end{array}$ & Республика Калмыкия, 2019 \\
\hline $\begin{array}{l}\text { Использование интерполяционного метода взве- } \\
\text { шенных обратных расстояний для визуализации } \\
\text { результатов оценочного зонирования, преобразо- } \\
\text { вание систем координат }\end{array}$ & Ленинградская область, 2019 \\
\hline
\end{tabular}




\section{Заключение}

Создание и дальнейшее использование в системе кадастровой оценки ГИС в регионах страны позволит обеспечить эффективность и качество проведения кадастровооценочных работ, а именно, в первую очередь, сформировать и поддерживать в актуальном состоянии единое хранилище графических и семантических данных кадастровой оценки, которое можно в дальнейшем использовать для целей актуализации сведений об объектах недвижимости в последующих турах оценки. Реализация данного мероприятия приведет к сокращению времени и трудозатрат на сбор актуальной и достоверной информации об объектах оценки. Разработка регионами собственной ГИС будет способствовать повышению достоверности и полноты исходных данных об объектах, частичной автоматизации процесса проведения кадастрово-оценочных работ, минимизации количества технических и методологических ошибок, повышению контроля обработки информации, расчета кадастровой стоимости, формирования отчетных материалов, а также значительно снизит временные и трудовые затраты.

Использование региональной ГИС позволит решить ряд проблем, затрудняющих проведение государственной кадастровой оценки, таких как отсутствие доступа к информации о сделках, которые регистрируются в Росреестре; отсутствие полноценного информационного взаимодействия исполнительных органов государственной власти с бюджетными организациями, выполняющими кадастровую оценку; неорганизованность, недостаточная полнота и достоверность сведений об объектах недвижимости, предоставленных различными исполнительными органами государственной власти. Тем самым применение ГИС в процедуре кадастровой оценки в регионах страны будет способствовать обеспечению высокой результативности выполнения оценочных работ, а, следовательно, и получению адекватной стоимости объектов оценки в целях реализации социальноадаптированной и экономически обоснованной системы налогообложения недвижимого имущества.

Проведенные исследования дали возможность проследить взаимосвязь использования ГИС-технологий в кадастровой оценке с возможностями управления визуализацией и структурированностью информации, а следовательно, повышения эффективность ее обработки и анализа. Подобная информационная система позволит оценщику эффективно проводить анализ рынка недвижимости любой требуемой глубины и мониторинг его состояния для различных целей оценки.

\section{Список источников}

1. Грибовский С.В. 2017. Оценка стоимости недвижимости: Учебное пособие. 2-е изд., испр. и доп. М., ООО «Про-Аппрайзер» Онлайн, 472 с.

2. Массовая оценка. Электронный ресурc. URL: http://pkmo.ru/pkmo/ (дата обращения: 14 ноября 2019). 2019).

3. QGIS. Электронный pecypc. URL: https://qgis.org/ru/site/ (дата обращения: 14 ноября

4. MapInfo. Электронный pecypc. URL: http://mapinfo.ru/ (дата обращения: 14 ноября 2019).

5. Федеральная служба государственной регистрации, кадастра и картографии (Росреестр). Электронный ресурс. URL: https://rosreestr.ru/site/ (дата обращения: 13 ноября 2019).

\section{Список литературы}

1. Грибкова И.С., Пастухов М.А. 2017. Применение возможностей ГИС для целей оценки недвижимости. Сборник материалов II международной научно-практической конференции. СанктПетербург, Издательство "Политехника": 431-437.

2. Гридина Е.А., Гридин А.В. 2016. Некоторые проблемы налогообложения имущества физических лиц. Международная научно-практическая конференция. Уфа: 46-48.

3. Головина О.А. 2018. Критерии оценки качества информационной базы государственной кадастровой оценки земельных участков. Молодой учёный, 50 (236): 229-231. 
4. Журавель В.В., Осипов П.А., Осипова Я.С., Димухаметов М.О., Осипова Д.А. 2017. WEB-технологии и ГИС на примере геопорталов и WEB-ГИС-серверов. Международная научнопрактическая конференция. Пенза: 115-117.

5. Козырев А.А., Шумаева К.В. 2019. Автоматизация подготовительного этапа проведения кадастровой оценки земель методом сегментирования объектов в QUANTUM GIS. Bсероссийская научно-практическая конференция. Краснодар, Эпомен: 412-420.

6. Лаврова М.И., Ефанова Д.А. 2016. Государственная кадастровая оценка: обзор проблем и причины неправильной оценки объектов недвижимости. Международная научно-практическая конференция. Уфа: 193-195.

7. Малюк К.Ю. 2017. Налогооблажение земельных участков. Студенческая научнопрактическая конференция. Ставрополь: 122-123.

8. Осенняя А.В., Будагов И.В., Хахук Б.А. 2017. Кадастровая оценка объектов недвижимости в современных условиях. Международная научно-практическая конференция. Белгород: 85-89.

9. Пастухов М.А. 2018. Применение ГИС с целью определения дифференциальной ренты I. Материалы V Международной научно-практической конференции. Пенза: 138-141.

10. Петров В.И. 2018. Оценка стоимости земельных участков. М., Кнорус, 286 с.

11. Салин В.Н. 2017. Методология статистического мониторинга кадастровой стоимости недвижимости: монография. М., Кнорус, 280 с.

12. Суровцов М.М., Губадеева Н.М., Клесова А.Ю. 2017. Земельный налог: проблемы исчисления по кадастровой стоимости земельного участка. Корпоративная экономика, 2 (10): 66-72

13. Ширина Н.В., Затолокина Н.М., Зенина Д.С. 2016. Исследование результатов государственной кадастровой оценки земель населенных пунктов и оценка эффективности налогообложения. Вестник Белгородского государственного технологического университета им. В.Г. Шухова, 3 : 228-231.

14. Osennyaya A.V., Khakhuk B.A., Gura D.A., Khusht N.I., Kuadze A.Ch., Kushu A.A. 2019a. Analysis of the results of cadastral valuation of buildings, premises, construction in progress and parking spaces for 2018 in the Krasnodar territory. Religación. Revista de Ciencias Sociales y Humanidades, 4 (18): 293-297.

15. Osennyaya A.V., Hahuk B.A., Gura D.A., Khusht N.I., Kuadze E. Ch., Shishkina V.A. 2019b. Modern system of taxation of real estate objects. Religación. Revista De Ciencias Sociales Y Humanidades, 4 (18): 298-302.

\section{References}

1. Gribkova I.S., Pastukhov M.A. Primenenie vozmozhnostey GIS dlya tseley otsenki nedvizhimosti [Application of GIS capabilities for real estate valuation]. Sbornik materialov II mezhdunarodnoy nauchno-prakticheskoy konferentsii. Sankt-Peterburg, Izdatelstvo "Politekhnika" - Collection of materials of the II international scientific and practical conference. St. Petersburg, Polytechnic Publishing House: 431-437.

2. Gridina E.A., Gridin A.V. 2016. Nekotorye problemy nalogooblozheniya imushchestva fizicheskikh lits [Some problems of taxation of property of individuals]. Mezhdunarodnaya nauchnoprakticheskaya konferentsiya. Ufa - International Scientific and Practical Conference. Ufa: 46-48.

3. Golovina O.A. 2018. Kriterii otsenki kachestva informatsionnoy bazy gosudarstvennoy kadastrovoy otsenki zemel'nykh uchastkov [Criteria for assessing the quality of the information base of the state cadastral valuation of land]. Molodoy uchenyy - Young scientist, 50 (236): 229-231.

4. Zhuravel' V.V., Osipov P.A., Osipova Ya.S., Dimukhametov M.O., Osipova D.A. 2017. WEBtekhnologii i GIS na primere geoportalov i WEB-GIS-serverov [WEB-technologies and GIS by the example of geoportals and WEB-GIS-servers]. Mezhdunarodnaya nauchno-prakticheskaya konferentsi-ya. Penza - International Scientific and Practical Conference. Penza: 115-117.

5. Kozyrev A.A., Shumaeva K.V. 2019. Avtomatizatsiya podgotovitel'nogo etapa provedeniya kadastrovoy otsenki zemel' metodom segmentirovaniya ob"ektov v QUANTUM GIS [Automation of the preparatory phase of the cadastral valuation of land by segmenting objects in QUANTUM GIS]. Vserossiyskaya nauchno-prakticheskaya konferentsiya. Krasnodar, Epomen - All-Russian Scientific and Practical Conference. Krasnodar, Epomen: 412-420.

6. Lavrova M.I., Efanova D.A. 2016. Gosudarstvennaya kadastrovaya otsenka: obzor problem i prichiny nepravil'noy otsenki ob"ektov nedvizhimosti [State cadastral valuation: a review of the prob- 
lems and the reasons for the incorrect valuation of real estate]. Mezhdunarodnaya nauchnoprakticheskaya konferentsiya. Ufa - International Scientific and Practical Conference. Ufa: 193-195.

7. Malyuk K.Yu. 2017. Nalogooblazhenie zemel'nykh uchastkov [Taxation of land]. Studencheskaya nauchno-prakticheskaya konferentsiya. Stavropol' - Student scientific and practical conference. Stavropol: 122-123.

8. Osennyaya A.V., Budagov I.V., Khakhuk B.A. 2017. Kadastrovaya otsenka ob"ektov nedvizhimosti $\mathrm{v}$ sovremennykh usloviyakh [Cadastral valuation of real estate in modern conditions]. Mezhdunarodnaya nauchno-prakticheskaya konferentsiya. Belgorod - International Scientific and Practical Conference. Belgorod: 85-89.

9. Pastukhov M.A. 2018. Primenenie GIS s tsel'yu opredeleniya differentsial'noy renty I [The use of GIS to determine differential rent I]. Materialy V Mezhdunarodnoy nauchno-prakticheskoy konferentsii - Materials of the V International Scientific and Practical Conference. Penza: 138-141.

10. Petrov V.I. 2018. Otsenka stoimosti zemel'nykh uchastkov [Assessment of the cost of land]. M., Knorus - Moscow, Knorus, 286 p.

11. Salin V.N. 2017. Metodologiya statisticheskogo monitoringa kadastrovoy stoimosti nedvizhimosti: monografiya [Methodology of statistical monitoring of the cadastral value of real estate: monograph]. M., Knorus - Moscow, Knorus, 280 p.

12. Surovtsov M.M., Gubadeeva N.M., Klesova A.Yu. 2017. Zemel'nyy nalog: problemy ischisleniya po kadastrovoy stoimosti zemel'nogo uchastka [Land tax: problems of calculating the cadastral value of a land plot]. Korporativnaya ekonomika - Corporate economics, 2 (10): 66-72.

13. Shirina N.V., Zatolokina N.M., Zenina D.S. 2016. Issledovanie rezul'tatov gosudarstvennoy kadastrovoy otsenki zemel' naselennykh punktov i otsenka effektivnosti nalogooblozheniya [Study of the results of the state cadastral valuation of land in settlements and assessment of the effectiveness of taxation]. Vestnik Belgorodskogo gosudarstvennogo tekhnologicheskogo universiteta im. V.G. Shukhova Bulletin of the Belgorod State Technological University. V.G. Shukhov, 3: 228-231.

14. Osennyaya A.V., Khakhuk B.A., Gura D.A., Khusht N.I., Kuadze A.Ch., Kushu A.A. 2019a. Analysis of the results of cadastral valuation of buildings, premises, construction in progress and parking spaces for 2018 in the Krasnodar territory. Religación. Revista de Ciencias Sociales y Humanidades, 4 (18): 293-297.

15. Osennyaya A.V., Hahuk B.A., Gura D.A., Khusht N.I., Kuadze E. Ch., Shishkina V.A. 2019b. Modern system of taxation of real estate objects. Religación. Revista De Ciencias Sociales Y Humanidades, 4 (18): 298-302.

\section{ИНФОРМАЦИЯ ОБ АВТОРЕ}

Осенняя А.В., доцент, кандидат технических наук, заведующий кафедрой кадастра и геоинженерии Кубанского государственного технологического университета, г. Краснодар, Россия

Грибкова И.С., старший преподаватель кафедры кадастра и геоинженерии Кубанского государственного технологического университета, г. Краснодар, Россия

Хахук Б.А., кандидат экономических наук, доцент кафедры кадастра и геоинженерии Кубанского государственного технологического университета, г. Краснодар, Россия

Бацких Т.А., студент кафедры кадастра и геоинженерии Кубанского государственного технологического университета, г. Краснодар, Россия

Воронова К.В., студент кафедры кадастра и геоинженерии Кубанского государственного технологического университета, г. Краснодар, Россия

\section{INFORMATION ABOUT THE AUTHOR}

Anna V. Osennaya, associate Professor, candidate of technical Sciences, head of the Department of cadastre and geoengineering of Kuban state technological University, Krasnodar, Russia

Irina S. Gribkova, senior lecturer, Department of cadastre and geoengineering, Kuban state technological University, Krasnodar, Russia

Bela A. Khakhuk, candidate of economic Sciences, associate Professor of the Department of cadastre and geoengineering of Kuban state technological University, Krasnodar, Russia

Tatyana A. Batskikh, student of the Department of cadastre and geoengineering of Kuban state technological University, Krasnodar, Russia

Kseniya V. Voronova, student of the Department of cadastre and geoengineering of Kuban state technological University, Krasnodar, Russia 